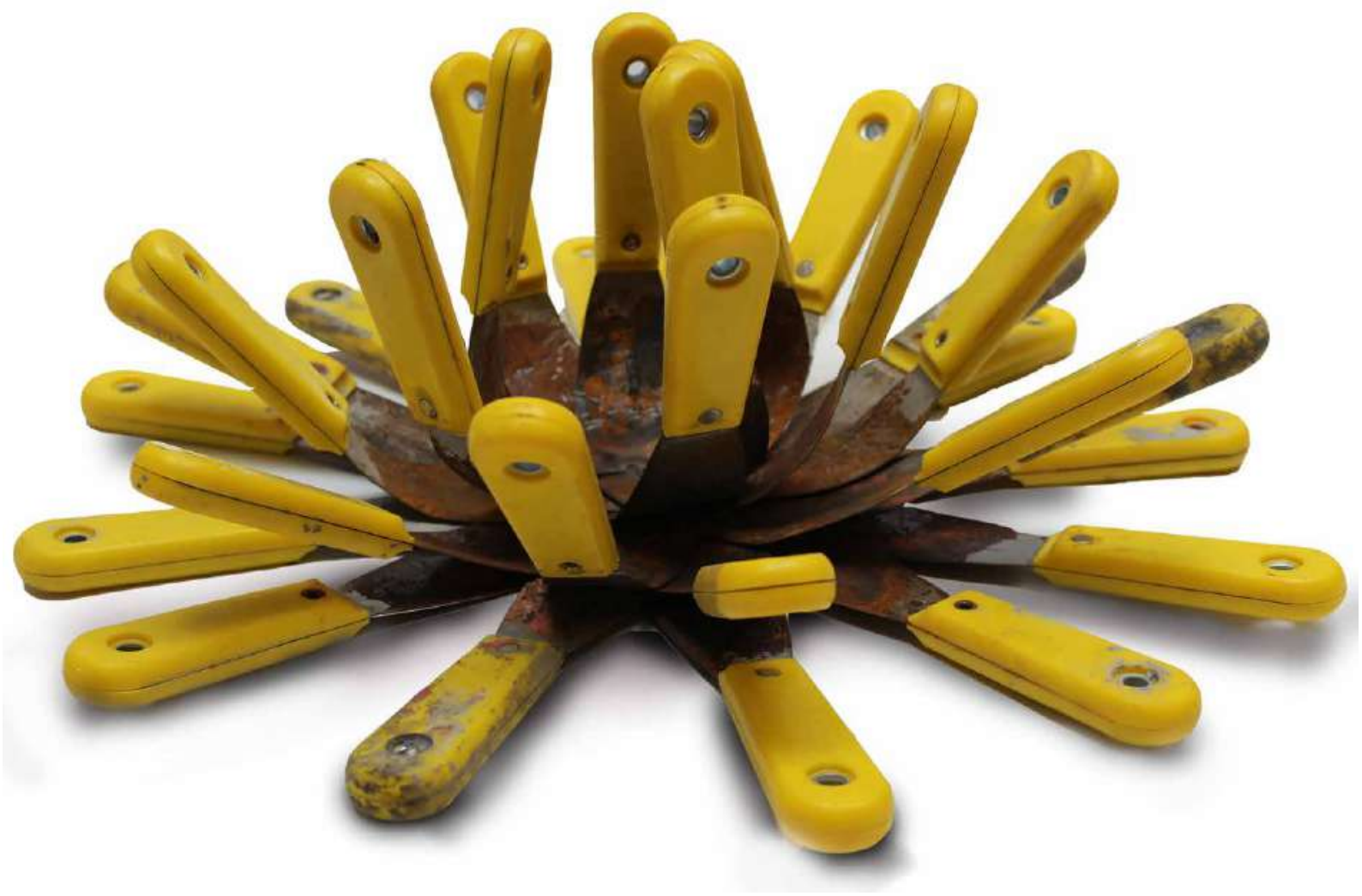

Yamith Quiroz David

Nuevas vegetaciones III

De la serie El mito de flora

Escultura, espátulas de hierro con cabos de pasta

$53,3 \times 52,4 \times 12 \mathrm{~cm}$

2020

Medellín 


\title{
Los paisajes de la transición en Colombia. El caso del Consejo Comunitario de los ríos La Larga y Tumaradó, Chocó*
}

\author{
Julián Salazar Gallego (Colombia)** \\ Julián Esteban García Romero (Colombia)***
}

\section{Resumen}

Este artículo analiza la forma en que se entrelazan múltiples escenarios transicionales y conflictos de diversa índole en la cotidianidad de los habitantes del Consejo Comunitario de los Ríos La Larga y Tumaradó, Chocó. Estos escenarios son producto de dispositivos de justicia transicional que operan en el territorio colectivo los cuales operan en medio del recrudecimiento del conflicto armado como efecto colateral del escenario de transición del Acuerdo de Paz de La Habana. Se parte de la hipótesis de que la vivencia de tal proceso está marcada por la tensión entre una serie de discursos y procedimientos técnicos del sistema-Estado y expresiones o mecanismos del derecho propio y autogobierno, los cuales se ubican al margen del derecho hegemónico. Al tomar elementos analíticos de la sociología jurídica y la antropología del Estado, se logró hallar que los dispositivos de justicia transicional, al ensamblarse localmente, sufren un dislocamiento y los(as) líderes(as) viven procesos de subjetivación política étnica que generan un pluralismo jurídico transicional.

\section{Palabras clave}

Conflicto Armado; Justicia Transicional; Territorio Colectivo; Sistema-Estado; Subjetividades Políticas Étnicas; Pluralismo Jurídico Transicional.

Fecha de recepción: marzo de 2020 • Fecha de aprobación: julio de 2020

\footnotetext{
* Este artículo es producto del proceso de investigación que la línea Gestión del Territorio en el Pacífico (GTP), del Centro de Investigación y Educación Popular Programa por la Paz (CINEP/PPP), Colombia, ha realizado por más de diez años al Consejo Comunitario de los ríos La Larga y Tumaradó.

** Abogado con profundización en Teoría Jurídica. Magíster en Derechos Humanos y Democratización. Investigador del equipo Gestión de Territorio en el Pacífico (GTP), del Centro de Investigación y Educación Popular Programa por la Paz (CINEP/PPP), Colombia. Correo electrónico: jsalazar@cinep. org.co

*** Politólogo con énfasis en resolución de conflictos e investigación para la paz. Antropólogo con énfasis en cultura y poder. Magíster en Sociología Política. Investigador del equipo Gestión de Territorio en el Pacífico (GTP), del Centro de Investigación y Educación Popular Programa por la Paz (CINEP/PPP), Colombia. Correo electrónico: jgarcia@cinep.org.co - Orcid: 0000-0003-0818-6818
} 


\title{
Cómo citar este artículo
}

Salazar Gallego, Julián y García Romero, Julián Esteban. (2020). Los paisajes de la transición en Colombia. El caso del Consejo Comunitario de los ríos La Larga y Tumaradó, Chocó. Estudios Políticos (Universidad de Antioquia), 59, pp. 124-148. DOI: 10.17533/udea.espo.n59a06

\section{The Landscapes of the Transition in Colombia. The Case of the Community Council of La Larga and Tumaradó Rivers, Chocó}

\begin{abstract}
This article analyzes the way in which multiple transitional scenarios and conflicts of various kinds intertwine in the daily lives of the inhabitants of the Community Council of La Larga and Tumaradó Rivers, Chocó. These scenarios are the product of transitional justice devices that operate in the collective territory, which work in the middle of the recruitment of the armed conflict as a result of the transition scenario of the Havana Peace Agreement. According to the starting hypothesis, the experience of such a process is marked by the tension between a series of discourses and technical procedures of the State-system and expressions or mechanisms of the proper and self-governing law, which do not make part of the hegemonic law. Through analytical elements from legal sociology and the anthropology of the State, it was possible to find that transitional justice devices, when assembled locally, suffer a dislocation, and the leaders endure processes of ethnic political subjectivation that generate a transitional legal pluralism.
\end{abstract}

\section{Keywords}

Armed Conflict; Transitional Justice; Collective Territory; System-State; Ethnic Political Subjectivities; Transitional Legal Pluralism. 


\section{Introducción}

La subregión del bajo Atrato se encuentra ubicada en el pacífico chocoano, es una zona húmeda con altas temperaturas, caracterizada por sus recursos hídricos, de allí que su arteria principal sea el río Atrato, irrigando un sinnúmero de cuencas que atraviesan los territorios ubicados en las márgenes del río (Jimeno, Sotomayor y Valderrama, 1995). Estas cuencas se constituyen en las principales fuentes de vida, gracias a que son espacios vitales donde las comunidades interactúan y llevan a cabo sus actividades cotidianas. Por esta razón, la vida de muchos de los consejos comunitarios circunvecinos al río guarda una estrecha relación con las cuencas que atraviesan su territorio, permitiendo una economía local de intercambio a baja escala.

Tras este telón de fondo, el Consejo Comunitario de los Ríos La Larga y Tumaradó (Cocolatu) se ubica en el Chocó biogeográfico, caracterizado por una gran biodiversidad y valiosos recursos genéticos, tiene un muy significativo valor ambiental y hace parte de uno de los ecosistemas estratégicos del país (Incora, 2000a, p. 72). Ubicado en el municipio de Riosucio, Chocó, Cocolatu fue titulado en el año 2000 (Incora, Resolución 02805 del 22 de noviembre de 2000) con una extensión de 107064 hectáreas y una población [126] aproximada de 5790 personas, ubicadas en 49 comunidades. Su poblamiento obedece a diversas dinámicas, entre ellas la de tipo ancestral asentada en el territorio, así como a diferentes oleadas de colonización provenientes del bajo y alto Baudó: «campesinos procedentes de Antioquia y de Córdoba que en búsqueda de tierras fértiles se han quedado en el territorio expandiendo la frontera agrícola, así como de fuerza de trabajo que ha arribado a las haciendas ganaderas y grandes empresas de monocultivos» (Sharp, 1993, p. 410). El proceso de poblamiento y colonización produjo una heterogeneidad de sujetos que habitan el territorio colectivo.

Las dinámicas del conflicto armado en el bajo Atrato y en el Urabá antioqueño no fueron ajenas al territorio colectivo de Cocolatu. A partir de la relación inescindible entre el sujeto colectivo y el territorio, sus habitantes experimentaron la violencia en la limitación al goce efectivo de sus derechos étnico-territoriales, generando una transformación radical en la experiencia del espacio desde la década de 1980 hasta la actualidad (Cinep/PPP, 2015). Por lo cual, un inventario de violaciones a los derechos humanos, al derecho internacional humanitario y de acciones bélicas en Cocolatu no puede leerse como un mero y simple hecho jurídico, despojado de su realidad 
territorial y de sus impactos en la cotidianidad, de acuerdo con los procesos de desterritorialización, cambio en los universos simbólicos, relaciones socioambientales, entre otros.

Las graves violaciones a los derechos humanos en contra de las comunidades negras que habitaban Cocolatu «obligaron al desplazamiento forzado masivo de cerca del $96 \%$ de los pobladores con el consecuente abandono de tierras» (Guerrero, 2018). Esta situación, en conjunto con la precaria presencia estatal en el territorio y, en general, en toda la zona del bajo Atrato, permitió que grupos al margen de la ley — guerrillas y paramilitaresy personas ajenas a la comunidad comenzaran a ocupar y usufructuar el territorio con fines contrarios a lo dispuesto en la Ley 70 del 27 de agosto de 1993. Una vez se generó el vaciamiento de comunidades enteras, se instalaron en el territorio colectivo proyectos agroindustriales como palma de aceite, plátano, arroz y ganadería extensiva. Estos hechos permiten la identificación de dos realidades:

a) La recreación de un discurso por parte del Estado, los grupos armados y actores económicos de que el bajo Atrato es una zona estratégica con potencial desarrollo económico, especialmente de economías de enclave, lo que obedece a que históricamente la construcción de la región se caracterizó por constantes choques entre diversas formas de ver el territorio, modelos de sociedad disímiles y proyectos políticos, económicos y sociales en constante tensión (Cinep/PPP, 2015).

Este discurso se torna verosímil en las versiones libres de los excomandantes de las Autodefensas Unidas de Colombia (AUC), los cuales esgrimen que las tierras de las comunidades negras son tierras improductivas y, por lo tanto, deben ser puestas a producir por medio de monocultivos. Esto último es una expresión del racismo estructural y la discriminación hacia los grupos étnicos que proviene desde la época colonial. «El verdadero objetivo del conflicto en algunas regiones del país, como en el Urabá, [...] no era combatir a la guerrilla, sino reactivar la economía bananera. Otro objetivo era apoderarse de miles de hectáreas de tierra productiva, [...] hectáreas para el cultivo de palma» (Comisión Colombiana de Juristas, 2011, p. 89).

b) La esperanza de haber obtenido la titulación colectiva de estos territorios se diluyó ante una dinámica de violencia caracterizada por una simbiosis entre desplazamiento y despojo. Como si fuera poco, la continuidad del conflicto propició una segunda ola de desplazamiento y desarraigo del 
territorio por parte de las comunidades. De esta forma, las comunidades negras de Cocolatu han sufrido un continuum de violencia, donde se entrelazan la opresión y discriminación ejercida en la época colonial con la impuesta actualmente por los actores armados que se disputan el territorio. En suma, la titulación colectiva de estos territorios fue poco eficaz debido a la ocupación que hacen empresarios, terratenientes y grupos armados.

Todos estos hechos victimizantes buscaron ser investigados, juzgados y reparados mediante variados dispositivos de justicia transicional: «los dispositivos de justicia transicional abren escenarios transicionales, es decir, espacios sociales que se gestan producto de leyes o acuerdos transitorios, y que se caracterizan por ser una suerte de ensambles de prácticas institucionales y discursos expertos entrecruzados en un contexto histórico concreto» (Castillejo, 2017, p. 65). De esta forma, leyes como la 387 del 18 de julio de 1997, la 975 del 25 de julio de 2005, la 1448 del 10 de junio de 2011 y el Acuerdo de Paz de La Habana (Gobierno y FARC-EP, 2016), son dispositivos que operan simultáneamente, en el caso de Cocolatu, generando tensos y complejos espacios sociales. El entrecruzamiento de estos dispositivos tiene lugar en la cotidianidad de las comunidades, al verse envueltas en diversos trámites, prácticas, espacios y lenguajes técnicos propios del derecho hegemónico, producido y codificado por el Estado — como los derechos humanos-. Sumado a esto, luego de la firma de los acuerdos y posterior implementación se evidencia como, debido a la desmovilización de las FARC de sus territorios de incidencia, se generó una disputa por el control territorial a lo largo y ancho del río Atrato, trayendo una crisis humanitaria denunciada tanto por entidades estatales (Defensoría del Pueblo, 2020, marzo 6) como por organizaciones no gubernamentales y la Iglesia católica (Osorio, 2019, agosto 2).

Este escenario genera la pregunta, ¿cómo viven el proceso de transición los miembros del Consejo Comunitario de los Ríos La Larga y Tumaradó? Para responder, el marco analítico utilizado toma aportes de la sociología jurídica y la antropología política, lo cual se decanta por lo que Alejandro Castillejo (2014) denomina «etnografías de lo transicional». Los trabajos de Pierre Bourdieu (2000), Julieta Lemaitre (2019; 2009) y Itzar Ruiz-Giménez (2012) permiten comprender el derecho como un saber técnico y profesionalizado inmerso en relaciones sociales y entramados de poder, en los cuales los sujetos se disputan sus significados. Esto se complementa con aportes de Veena Das y Deborah Poole (2008), Philip Abrams (2015), Akhil Gupta (2015) y Michel- 
Rolph Trouillot (2001), los cuales no conciben al Estado como una entidad homogénea, monolítica y superior a la sociedad, sino que este se materializa en una serie de prácticas y lenguajes institucionalizados en las interacciones cotidianas. Dando como resultado aquello que Abrams (2015, p. 51) denominan ""el sistema-Estado" (sistema institucionalizado de prácticas) que son las formas materiales en las que este se objetiva».

El marco analítico usado tiene un fuerte enfoque relacional, analizando de manera etnográfica las relaciones sociales que se gestan al interior de escenarios transicionales. A partir de las interacciones y las prácticas cotidianas, se busca comprender la manera como sociedades concretas conciben su relación con el pasado e imaginan el futuro como posibilidad. Al hablar de cotidianidad se refiere a encuentros cara a cara estructurados, que obedecen tanto a estructuras sociales más amplias como a patrones de interacción social que tienen definidos ciertos repertorios de interacción (Goffman, 1959; Schutz, 1993). La investigación es un esfuerzo por acuñar lo que aquí se denomina pluralismo jurídico transicional, es decir, una forma de reconocer y legitimar formas de derecho no estatal que han sido marginalizadas e ignoradas por el derecho hegemónico, y que constituyen un relato polifónico sobre las formas de entender el pasado y construir el futuro.

La estrategia metodológica usada es el método cualitativo y el estudio de caso simple. Ambos permiten develar y comprender las múltiples interacciones de los actores, su significado y cómo fluyen y cambian a lo largo del tiempo (Cohen y Piovani, 2008). Sumado a esto, el método cualitativo tiene la ventaja de implementar diseños flexibles en la investigación, es decir, se generan cambios en el marco analítico y la hipótesis de acuerdo a los datos que van emergiendo de la interpretación y análisis de la información empírica (García, 2019).

Las técnicas de investigación para recabar información fueron las entrevistas semiestructurada a diez miembros de la junta directiva y a líderes(as) de comunidades, ${ }^{1}$ y la observación participante. En las entrevistas confluyen las experiencias, sentimientos, subjetividades e interpretaciones que cada persona hace de su vida y de la vida social —fenómeno multidimensional—.

\footnotetext{
${ }^{1}$ A cada uno de los participantes les fue socializado el objetivo de la entrevista y suscribieron un consentimiento informado, también se acordó la confidencialidad de su identidad por motivos de seguridad.
} 
Por su parte, la observación fue controlada y sistemática, ${ }^{2}$ donde el rol como investigadores acordado fue el de «participantes completos» (Guber, 2008). Esto debido a que los autores son integrantes del equipo de trabajo de la organización no gubernamental que ha acompañado y asesorado a Cocolatu por más de diez años, es por esto que la interacción que se entabló con funcionarios públicos y comunidades fue vivencial: «El único medio para acceder a esos significados que los sujetos negocian e intercambian, emiten y reciben, es la vivencia, la posibilidad de experimentar en carne propia esos sentidos, como lo hacen todos los individuos en su socialización» (Guber, 2008, p. 111).

\section{El universo de dispositivos de justicia transicional}

El sistema-Estado colombiano de manera paulatina fue respondiendo a la guerra y al desplazamiento forzado a través de diferentes dispositivos transicionales. En un primer momento, por medio de la Ley 387 de 1997 implementó una serie de medidas para mitigar la crisis humanitaria generada por las crecientes olas de desplazados; sin embargo, a mediados de la década del 2000 el enfoque de asistencia humanitaria fue reemplazado por el primer dispositivo de justicia transicional denominado Ley de Justicia y Paz (Ley

[130] 975 de 2005). ${ }^{3}$ Posteriormente, el Estado colombiano adoptó la Ley 1448 de 2011 (Ley de Víctimas y Restitución de Tierras), con la cual proyectó un programa de reparación administrativa a las víctimas del conflicto armado, entregándoles un monto de dinero por el hecho victimizante; adicionalmente, se propuso un ambicioso programa de restitución de tierras que habían sido abandonadas y despojadas. ${ }^{4}$

Estos discursos transicionales ${ }^{5}$ se elaboraron a partir del trasplante de lo que es definido en el ámbito global por los formuladores de política pública, donantes, organismos multilaterales y la academia justicia transicional: «es decir, como una herramienta que tiene la capacidad de afrontar graves crímenes del pasado que fueron cometidos en momentos de dictadura o guerra, protegiendo los derechos de las víctimas a la verdad, justicia, reparación y garantías de no repetición» (Teitel, 2004, p. 69). Estos mecanismos implican una serie de tecnologías como tribunales de justicia, comisiones de la verdad, programas de reparación que son agenciados por un gran aparato técnico burocrático.

La imbricación de estos dispositivos recreó un paisaje normativo al interior de Cocolatu, de tal forma que el registro de la guerra y la administración 
del pasado, presente y futuro es construido desde diferentes aristas. El primer momento se afincó en los juicios penales a los jefes paramilitares bajo la Ley de Justicia y Paz. En el marco de las versiones libres, Raúl Emilio Hasbún Mendoza, jefe del Frente Alex Hurtado, develó las dinámicas de violencia sistemática ocurridas en el bajo Atrato, en donde el desplazamiento forzado operó como una estrategia para el despojo de tierras y la implantación de proyectos agroindustriales (Tribunal Superior de Medellín, Sentencia 110016000253200883241 del 27 de agosto de 2014, p. 49).

Por otra parte, debido al déficit de verdad en el proceso judicial, fue necesario complementarlo con una reconstrucción de la verdad histórica a cargo del Centro Nacional de Memoria Histórica (CNMH), a partir del reconocimiento de las afectaciones étnico-territoriales causadas al sujeto colectivo en el marco del conflicto armado. En un primer momento, la reconstrucción del impacto del conflicto armado en Cocolatu se tejió por medio de la superposición de la verdad judicial generada por los juicios penales de Justicia y Paz, y por la verdad extrajudicial narrada por el CNMH.

El segundo momento parte de la implantación de la Ley 1448 y sus decretos reglamentarios, bajo este dispositivo transicional tanto víctimas individuales como sujetos colectivos tuvieron la oportunidad de recuperar sus territorios. Así, en Cocolatu se encuentra un proceso colectivo de restitución de derechos étnico-territoriales bajo el Decreto 4635 del 9 de diciembre de 2011, y se desarrollan paralelamente solicitudes individuales en el marco de la Ley 1448 de colonos campesinos que obtuvieron sus predios antes de la titulación colectiva en el año 2000.

El tercer momento se erige a partir de la firma del Acuerdo de Paz de La Habana entre el Gobierno colombiano y la guerrilla de las FARC, donde se creó un complejo sistema de justicia transicional. Este sistema es una ventana de oportunidad para Cocolatu, ya que es un escenario de incidencia y participación donde podrán obtener un mayor esclarecimiento de los hechos sucedidos en su territorio, a partir de su contribución a develar la responsabilidad e interacción entre terceros civiles responsables, como empresarios, actores económicos y agentes del conflicto armado.

La construcción de estas tecnologías transicionales se establece esencialmente sobre un saber técnico, profesionalizado y jerarquizado que «se caracteriza por la prevalencia de un lenguaje y acceso a recursos jurídicos agenciado por un cúmulo reducido de actores — como los abogados, jueces 
y expertos-, que parecen ser los únicos que tienen acceso a este campo» (Bourdieu, 2000, p. 160). En este derecho hegemónico, las narrativas jurídicas se tornan complejas a aquellos que no pertenecen al escenario jurídico - como las víctimas y personas del común- por el excesivo tecnicismo, construyendo una serie de barreras que impiden, en muchas ocasiones, el acceso a la justicia.

Posterior a que la funcionaria de la dirección de asuntos étnicos de la URT [Carolina Builes] hiciera un balance del proceso de restitución, se detuvo en el tema de acumulación de procesos individuales con el proceso colectivo. Mario comentó: "¿cómo va ese proceso de acumulación individual?, es que ya empezaron a llegar notificaciones para que el consejo se presente como opositor». El funcionario jurídico de la Dirección de Asuntos Étnicos [Alejandro Rodríguez] explica: "Con la sentencia de ACABA se abre toda una línea jurisprudencial que permite a la URT como su apoderado guiarse para sortear este asunto, en dicha sentencia se plantea que solo se acumularán los procesos que agoten la fase administrativa, por tal motivo, este proceso de acumulación solo se da cuando se haya agotado dicha etapa». Hubo un silencio ensordecedor, los miembros de la junta y líderes de otras comunidades se miraban entre sí, alzaban las cejas en ademán de perplejidad, se tocaban los rostros con sus manos. «Ese tema aún no lo entendemos, es muy enredado para nosotros, comentó Pablo» (nota de campo, reunión entre la URT y la junta directiva de Cocolatu, abril 14, 2019).

La racionalización de los dispositivos transicionales juridificó demandas y reivindicaciones de las víctimas por las violaciones a los derechos humanos ocurridas en el marco del conflicto. «El derecho por medio de un acto mágico absorbe y nomina estas realidades, otorgándole un nombre y un procedimiento específico en el marco de lo jurídico» (Derrida, 2008, p 52). Para este solo es relevante que el hecho pueda ser identificado e incorporado dentro de una de sus categorías, despojándolo del síntoma traumático de lo que implica perder a un ser querido, incluyendo los efectos psicoemocionales, el truncamiento de los proyectos de vida, el resquebrajamiento de las relaciones interpersonales y la erosión del tejido comunitario. «En últimas, para el derecho no existe un antes y un después, la obliteración de estos dos movimientos en el tiempo obtura la posibilidad de observar los procesos de duelo, sanación, reconstrucción de horizontes de vida y su carácter emocional» (Lemaitre, 2019, p. 173). 
Dicha racionalización determinó el itinerario de la justicia transicional, la cual no ofrece la misma importancia a todo el universo de víctimas, generando una jerarquización entre ellas, priorizando unos hechos sobre otros, lo que produce a su vez unas relaciones de poder que se disputan en la arena política y social entre diferentes hechos victimizantes que son abanderados por colectivos de diversa índole, con la intención de mostrar una mayor visibilidad mediática, generando repercusiones directas respecto del ritmo con el que la Justicia resuelve el caso:

Investigador: ¿Cómo ha sido el proceso de entender todo ese lenguaje y trámites de la restitución?

Marco: Pues yo fui líder comunitario y presidente de junta de comunidad, entonces tenía conocimiento de algunas cosas, pero tuve que pedir orientación de abogado para que le diera explicaciones de las palabras y trámites adecuados. A veces es muy enredado, pero toca entender porque el que no sabe es como el que no ve, queda perdido. Estos procesos son muy lentos [suspiro], ojalá esté vivo para cuando se dé el fallo (comunicación personal, Marco Ramírez, líder de la comunidad Villa Eugenia, septiembre 10, 2019).

Por otro lado, al ubicarse estos dispositivos en una temporalidad limitada, dejan de lado victimizaciones estructurales, las cuales son padecidas por las comunidades negras desde la época colonial y que inherentemente se entrelazan con las dinámicas de violencia actual, imperando el silenciamiento del sujeto subalterno, debido a los vectores de la confrontación armada y a la lucha contrainsurgente, donde la población civil fue la más afectada y el predominio de las élites en el poder buscaron callar a estos sujetos.

Este paradigma transicional paulatinamente se inoculó en los discursos de las víctimas y de las comunidades, especialmente desde las narrativas de los derechos a la verdad, justicia, reparación y garantías de no repetición. Muchas de ellas, desde sus arengas y luchas por la reivindicación de sus derechos, apropiaron estos conceptos desde los cánones de lo jurídico, especialmente desde la definición impuesta por las leyes transicionales, los instrumentos internacionales y las agencias gubernamentales encargadas de implementar la política de transición, por lo que su discurso tiende a enunciarse cada vez más desde lo legal, imbricándose con su experiencia subjetiva y vital en la lucha por recomponer sus proyectos de vida. Esto puede obedecer a la lógica de un imaginario colectivo de creer que la única vía para exigir y ser escuchadas son las vías legales, como el único camino legítimo para resistir, por lo que 
cada vez más la justicia transicional, como un espacio limitado por los marcos legales e institucionales, deja de ser leída como una panacea y el mecanismo por antonomasia que permite tejer escenarios de paz, para ser apenas un elemento que permite ampliar los distintos registros sobre la guerra.

La jornada continuaba en medio de las preguntas por parte de los líderes(as) de las diferentes comunidades aledañas a Villa Eugenia, el calor era sofocante, puesto que el medio día se acercaba. Los asistentes en su mayoría eran campesinos mestizos, «chilapos», ya que esta zona del consejo es en donde mayor cantidad de títulos individuales hay. Con los ánimos caldeados, una lideresa de la comunidad Bella Rosa les preguntó a los funcionarios de la URT: «yo quiero que ustedes, doctores, nos aclaren cómo van nuestros procesos de restitución individual, es que aquí hay personas que estamos por Ley 1448, otros están por la Ley 975, entonces nosotros queremos saber en qué va eso, si ya nuestros casos están en el registro de tierras despojadas o no, en qué etapa va. Por eso es que todos estamos acá, para tener claridad de eso, porque esto parece de no acabar, cada vez nos dicen que esperemos que tengamos paciencia, pero los años pasan y nada». Uno de los funcionarios contestó: «Este es un proceso muy complejo, tiene muchas aristas al haber títulos individuales en territorio colectivo" (nota de campo, reunión funcionarios URT y líderes comunidades de la zona 2, agosto 8, 2019).

También es posible reconocer que desde muchas organizaciones y comunidades en los territorios, a partir de sus experiencias vitales y de sus realidades territoriales, logran recrear nuevos órdenes de sentido que tienen la potencialidad de nombrar y resignificar realidades sociales, desde donde se tejen alternativas que lleven a forjar un futuro con esperanza capaz de reconocer como anormal la cotidianidad violenta. Las relaciones de pasado, presente y futuro son adjudicados — en una red de relaciones - a una serie de contenidos sociales basados no solo en las conceptualizaciones legales que circulan en la aplicación de la ley, sino también en los recursos narrativos y culturales que las organizaciones de diferente índole pueden tener a la mano (Castillejo, 2017).

Lo anterior sugiere una lectura del derecho como un medio a través del cual se reproducen diversos tipos de identidades, gracias al carácter dual que tiene el derecho, de dominación y de resistencia (Fitzpatrick, 2011). Los espacios intersticiales de la vida cotidiana de los subalternos resultan ser clave para entender cómo estos consiguieron apropiarse de la legalidad dominante, 
adecuarla a sus propios lenguajes y en determinados momentos recurrir a ella para oponerse o cuestionarla (Sierra y Chenaut, 2014). De esta forma, el derecho se torna en una herramienta de legitimación de saberes y órdenes, que desde la cotidianidad agencian contrapoderes y resistencias.

\section{Transiciones traslapadas e inacabadas en el Consejo Comunitario de los Ríos La Larga y Tumaradó}

Esta amalgama de escenarios transicionales se superpone en una realidad territorial, en la que aún perviven situaciones de violencia a partir de las disputas por el control armado y por las rentas ilegales. La implementación de estos dispositivos, que se pensaba marcaría una fractura, implicó el resurgimiento de nuevas violencias, por lo que en lugar de ser un punto de inflexión son una continuidad de violencias crónicas que se acentúan sobre el conflicto histórico de la posesión, uso y titulación de la tierra, así como sobre una exclusión y discriminación estructural de las comunidades negras.

Investigador: ¿Cómo vive usted eso que llaman transición?

Martín: Yo esa transición no la vivo tan real como debiera ser. Cuando uno escucha hablando de paz uno dice. «bueno, ya vamos a volver a estar tranquilos en la finca, trabajando la tierra», pero eso no se ve ahora. Porque las FARC entrega las armas, se concentran en unos puntos, pero a la vez entran otros grupos armados. Eso no me da confianza que sea un proceso de paz serio, no vivo tampoco tranquilo porque ya me han amenazado. Yo lo llamaría de otra forma, pero no una transición hacia la paz (comunicación personal, Martín Guerrero, miembro de la junta directiva Cocolatu, septiembre 12, 2019).

Esta situación ha puesto a las comunidades en una paradoja, «entre el desconocimiento de los complejos procesos transicionales y la necesidad de recurrir al derecho como un vehículo de exigencia y de reivindicación de sus derechos» (Rodríguez y Baquero, 2015. p. 36.), lo que generó que muchas organizaciones de la sociedad civil iniciaran procesos de acompañamiento a estas comunidades basado en la formación y fortalecimiento de capacidades, procesos financiados por agencias de cooperación donde el interés de sus agendas está marcado por el rumbo global de la construcción de una paz liberal, implementando proyectos de gobernanza que «buscan incorporar los estados en transición hacia una democracia de mercado, que se propone el control del territorio y a la población, y se aporte orden y estabilidad» (RuizGiménez, 2012, p. 25). 
Sin embargo, en el proceso de investigación se evidencia que estos modelos de gobernabilidad y transición, a la hora de ser trasplantados localmente, sufren un dislocamiento a partir de la configuración cotidiana que se les otorga a conceptos como verdad, justicia y reparación. Esto coincide con lo planteado por Esteban Krotz (2014) para quien la justicia transicional es un campo de luchas que ocasionalmente permite victorias limitadas a quienes, en principio, no pertenecen a los segmentos poderosos de la sociedad que imponen estas reglas. Es así como las comunidades son un actor en la disputa por los significados, desde recursos culturales y narrativos que definen los propios contornos de estos conceptos. Por esta razón, comunidades negras como Cocolatu, desde un ejercicio de derecho propio y autogobierno que se ubica al margen del derecho hegemónico, generan una disrupción con el discurso transicional.

Investigador: ¿Cómo vive usted eso que llaman transición?

María: Acá en la cuenca de La Larga y Tumaradó vemos muy difícil esa transición, porque los grupos armados continúan y la presencia del Estado es muy poca, entonces uno no ve cambios sustanciales. Lo que uno ve es que continúa la violencia y la convivencia de nosotros con esos grupos, por eso nos toca a nosotros mismo organizarnos bajo nuestros reglamentos internos para que esos grupos no nos manden (comunicación personal, María López, lideresa de la comunidad de Macondo, septiembre 11, 2019).

Lo anterior implica un ejercicio de resignificación, es decir, un cambio de coordenadas sobre los discursos institucionales pregonados tanto por el sistema-Estado como por los organismos internacionales sobre lo transicional. Dibujando un nuevo mapa desde sus experiencias vitales y su entramado cultural que, a su vez, le otorgan un horizonte de sentido a estos conceptos, despojándolos de tecnicismos jurídicos. El agenciamiento del derecho propio es un medio para lograr cambios y generar nuevas lecturas e interpretaciones de la realidad, que contribuyan a deconstruir la normalidad de la violencia, creando ventanas de oportunidad que permitan posicionar las reivindicaciones de las comunidades negras (Lemaitre, 2009). La declaración de mandatos ancestrales en el reglamento interno de COCOLATU ejemplifica lo dicho:

Verdad: es el derecho de conocer con total certeza lo que ha ocurrido dentro del territorio. Nos permite hacer memoria y proyectarnos hacia el futuro. Al mismo tiempo, rompe con la memoria oficial que ha 
querido invisibilidad la realidad que hemos enfrentado, promoviendo el reconocimiento político de nuestra lucha por la defensa del territorio.

Reparación: apunta fundamentalmente a la reconstrucción y reivindicación de los sucesos y luchas de la comunidad afrodescendiente, el retorno a los lugares de origen abandonados y la restauración de las formas tradicionales de vida aportando la sanación, tanto individual como colectiva de los habitantes del territorio.

Justicia: reconocemos en la justicia una herramienta fundamental para alcanzar y consolidar un escenario de convivencia pacífica en el territorio colectivo y desde este con los demás actores que conforman la sociedad. Mediante el diálogo intercultural y el respeto mutuo, en busca de una sociedad incluyente que valora y respeta la diferencia y desde allí promueve la democracia (Cocolatu, 2018, p .13).

Es justamente allí donde las coordenadas se invierten y comienzan a jugar elementos fundamentales, como lo es el diálogo y la circulación de la palabra, permitiendo retejer las relaciones de compadrazgo, pertenencia y la gestión de los conflictos. A partir del diálogo se van esculpiendo estos significados, que a su vez interpelan los discursos hegemónicos, lo cual es muy diciente al concebir la verdad como una forma de romper la memoria oficial e incluir elementos restaurativos y sanadores en su concepción de reparación. Esto funciona como un mecanismo de inclusión, en la medida que contribuye a la integración de los miembros de la comunidad con un capital cultural diferenciado y una plataforma que les permite interlocutar con diferentes instituciones: juntas de acción comunal, consejos locales, organizaciones sociales y entes del Estado.

Estos preceptos resultan ser totalmente vacuos desde la óptica del discurso institucional, cobrando vida solo cuando son aprehendidos bajo el tejido cultural de las comunidades negras. El derecho propio, como un mecanismo performativo, permite constituir y nombrar realidades que antes no lo eran, recreando desde abajo un modo de vida constituido por sujetos sociales legitimadores de nuevas prácticas que envuelven creación, resistencia y reivindicación de derechos.

La reunión en la comunidad de La Punta tenía como fin entregar los reglamentos internos del Consejo Comunitario y hacer una pequeña socialización de estos. Luisa dio algunas palabras sobre el significado de estos: «nosotros como comunidades negras somos la máxima autoridad dentro de nuestro territorio colectivo, eso es gracias a lo que 
estipula la Ley 70 de 1993, allí muy claramente dice que nosotros como Consejo Comunitario somos autónomos y soberanos en este territorio. Por eso este reglamento es tan importante, porque aquí están las reglas que nos regulan a todos, si uno se fija en cada sección hay formas de resolver situaciones entre vecinos, sean mestizos o no. Es clave que ustedes como líderes lo lean y lo compartan con sus comunidades, para que nuestros problemas los podamos resolver entre nosotros» (nota de campo, reunión juna directiva Cocolatu y comunidades de La Punta, marzo 20, 2019).

Esta forma de producción del derecho desde abajo es una manera de «profanar» el orden jurídico hegemónico del derecho formal estatal. Existen unas maneras sociales y culturales de profanar el discurso legal y, por tanto, debilitar el campo jurídico y de afianzar la producción de un campo o sub campo jurídico distinto al hegemónico, abriendo una compuerta a maneras no convencionales de apropiación y agenciamiento de los distintos registros de la justicia transicional (Ariza, 2010). Estos nuevos registros podrían explicarse a través del pluralismo jurídico transicional, cuyo paradigma exige al sistemaEstado un silencio casi profundo — que deje de hablar para escuchar-, con miras a que otros significados de lo jurídico puedan manifestarse para lograr construir realidades normativas paralelas. El pluralismo jurídico transicional se constituye en una serie de prácticas socioculturales agenciadas por las comunidades para resignificar las lecturas del pasado, presente y futuro, abriendo la posibilidad de un espacio transicional. ${ }^{6}$

Dichas prácticas coexisten con las normas del derecho estatal, generando una interlegalidad, la cual es definida por Santos (2009) como una intersección de diferentes órdenes jurídicos. Esto significa que las normas del derecho estatal y las prácticas y normas de las comunidades negras se encuentran imbricadas, constituyéndose mutuamente en formas que implican el conflicto normativo, pero también la negociación y múltiples transacciones. En este sentido, el conjunto de normas que recrean la narrativa del pluralismo transicional se fija entre los intersticios del Estado y el poder local, respondiendo a los intereses y necesidades de la comunidad —creación y reconocimiento de los derechos fundamentales-. «Con el poder local se buscan reinventar formas más dinámicas, directas y participativas de gestión en un ámbito espacial delimitado, descentralizado y democrático, constituido por nuevos actores sociales, imbuidos de legitimidad y autonomía para la ejecución del control, la toma de decisiones y la práctica de servicios legales populares» (Wolkmer, 2002, p. 43). 


\section{La cotidianidad de la transición en los márgenes del sistema-Estado}

De esta forma, en el bajo Atrato el multiculturalismo y la etnización no solo han operado como una representación idealizada de las comunidades negras, sino que han insertado de forma prescriptiva un inusitado sujeto moral, que define cómo se debería ser, en franca distancia con lo que suele suceder (Restrepo, 2011, p. 61).

Como se mencionó al inicio, el bajo Atrato es una subregión habitada por una heterogeneidad de sujetos, entre ellos, campesinos mestizos o «chilapos» llegados de los departamentos de Córdoba y de Antioquia. Si bien en Cocolatu la convivencia entre comunidades negras y «chilapas» no es armoniosa, la Ley 70 de 1993 imprimió nuevas dinámicas, ya que los contenidos de esta tuvieron una interpretación racializada en varios Consejos Comunitarios vecinos, como los de Pedeguita y Mancilla y Curvaradó, en donde el ser afro está estrechamente ligado al color de piel y no a un proceso de autorreconocimiento. El proceso de etnización de las comunidades negras, entendida como «la formación de un sujeto político en un sentido amplio (un nosotros/ellos), y de unas subjetividades (unas identificaciones), en nombre de la existencia (supuesta o efectiva) de un "grupo étnico". Por tanto, entiendo por etnización el proceso en el cual unas poblaciones son constituidas y se constituyen como "grupo étnico"» (Restrepo, 2011, p. 5). Esto aumentó las tensiones con los campesinos colonos, ya que se crearon marcadores de diferencia que brindaban derechos sobre la tierra. De esta manera, la emergencia del sujeto político negro produjo una serie de dinámicas en los procesos organizativos de las comunidades.

Es evidente que, en el bajo Atrato, el multiculturalismo expresado en el proceso que condujo a la Ley 70 propició una serie de tensiones en las expresiones y dinámicas organizativas, que no existían antes de la etnización. En este sentido, el particular proceso de etnización que tiene lugar en el bajo Atrato, derivado del giro al multiculturalismo, constituye a un inusitado sujeto (las comunidades negras) que fractura los términos en los que venía consolidándose el imaginario político local en torno al campesino, e inserta un conflicto que antes no existía en el plano organizativo (Restrepo, 2011, p. 60).

Frente a este fenómeno se evidencian dos elementos en el caso de Cocolatu y en el proceso de restitución de tierras: por un lado, se argumenta 
que los «chilapos» deberían ser considerados como ocupantes de buena fe, pues muchos de ellos llegaron al bajo Atrato hace varias décadas y, en el estrecho contacto con las comunidades negras, se apropiaron de una buena parte de sus prácticas tradicionales, e incluso establecieron lazos de parentesco con miembros de estas, identificándose como afro; por otro lado, hay algunos «chilapos» que no se reconocen como parte de Cocolatu, formado organizaciones políticas paralelas, como las Juntas de Acción Comunal (JAC), estos conflictos interétnicos e intraétnicos coexisten mientras los dispositivos transicionales avanzan.

Sumado a estos conflictos, hay formas de violencia que actualmente persisten a pesar de la puesta en marcha de estos dispositivos de justicia transicional. La conjugación de conflictos interétnicos e intraétnicos y el traslape de tales dispositivos, le imprimen una serie de dinámicas a la cotidianidad de las personas que abanderan el proceso de restitución de derechos étnico-territoriales. Es así como en estos lugares concebidos como márgenes del sistema-Estado la cotidianidad transcurre en medio de tensiones que desgastan los procesos organizativos de Cocolatu.

Estos sitios no son meramente territoriales: son también (y quizás sea éste su aspecto más importante) sitios de práctica en los que la ley y otras prácticas estatales son colonizadas mediante otras formas de regulación que emanan de las necesidades apremiantes de las poblaciones, con el fin de asegurar la supervivencia política y económica (Das y Poole, 2008, p. 24).

Actualmente, las personas del territorio colectivo que adelantan procesos de restitución, ya sea por la vía individual o colectiva, son forzados a convivir con actores como las Autodefensas Gaitanistas de Colombia (AGC), la Fuerza Pública, empresarios y terratenientes que ocupan de manera ilegal sus tierras. La interacción durante años de estos actores genera órdenes sociales, los cuales son alterados por el avance del proceso de restitución, ocasionando tensiones de manera gradual en la cotidianidad.

En ese sentido, resulta apropiado pensar en los efectos producidos por estas interacciones, donde los límites entre lo estatal y lo no estatal se redefinen permanentemente. Es en la producción de estos efectos que el sistema-Estado se reifica en idea Estado. Por lo tanto, el Estado no se agota en el sector público, se trata también del conjunto de relaciones sociales que establece un orden social respaldado por la amenaza de la fuerza. Cocolatu, 
como órgano de gobernanza comunitaria, ve limitada sus funciones en la medida en que esos otros actores o poderes a la sombra le disputan la soberanía y la legitimidad de ser la autoridad étnico territorial. Según Lemaitre (2019), hay evidencia para pensar que lo que en realidad persiste es el orden social autoritario y violento establecido por los paramilitares, es decir, que se trata de una trayectoria trazada por las instituciones económicas y políticas que se impusieron en la guerra, y que se materializan en poderes en la sombra.

Investigador: ¿Cómo era el día a día de Oscar antes de empezar el proceso de restitución y cómo es esa rutina hoy?

Oscar: Yo antes trabajaba en una finca ganadera, como había prestado servicio fui escolta de un alcalde y después fui vigilante de un colegio. Cuando llegó la Ley 1448 empezamos a ir a la Unidad de Víctimas, tuvimos reuniones con abogados y funcionarios que nos explicaron lo que teníamos que hacer. Hoy mis días son diferentes, ahora tengo que estar en reuniones con las entidades de gobierno, con la UNP, URT, UARIV, capacitaciones y más reuniones, todo eso para gestionar y decirle a los demás líderes cómo va el proceso. El trabajo es difícil, ahora tengo problemas con los empresarios que ocupan nuestras tierras, tengo un esquema de seguridad y dos escoltas, se perdió la privacidad, se perdieron los amigos (comunicación personal, Oscar Rentería, líder de la comunidad de La Pala, septiembre 13, 2019).

De este testimonio se resaltan dos hallazgos: primero que el sistemaEstado no es una construcción suprahistórica o una entidad independiente de la sociedad, sino que es un proyecto inacabado que está entrelazado en la cultura y una densa red de relaciones sociales locales, lo cual está en sintonía con los postulados de Bob Jessop (2017), al entender el Estado como una relación social, es decir, el ejercicio del poder como «la condensación mediada institucional y discursivamente de un equilibrio de fuerzas que es variable de acuerdo a coyunturas específicas vinculadas a un entorno natural y social más amplio» (p. 34).

De allí que resulte clave usar un enfoque relacional para estudiar las transiciones de manera histórica y etnográficamente, lo que implica tanto el análisis de las prácticas cotidianas de las burocracias locales, como la construcción discursiva del Estado en la cultura pública a través del tiempo. Sustancialmente, permite desagregar al Estado, centrándose en diferentes burocracias sin prejuzgar sobre su unidad y coherencia, «asimismo, permite 
problematizar la relación de la translocalidad de "el estado" y las oficinas, instituciones y prácticas necesariamente localizadas por las que éste está ejemplificado» (Gupta, 2015, p. 73).

En esta misma dirección, Trouillot (2001) afirma que, al no tener fijeza institucional o geográfica, los efectos y representaciones del Estado van más allá de las instituciones gubernamentales o nacionales, lo que hace necesario enfocar el análisis en los múltiples sitios donde son reconocibles los procesos y las prácticas estatales, es decir, en algo más abierto al estudio por medio de estrategias etnográficas: «si nos enfocamos en los efectos del Estado a través de la experiencia vivida de los sujetos podemos descubrir cuándo y cómo se logran estos efectos, sus condiciones de producción y sus límites» (p. 167).

El segundo hallazgo tiene que ver con que la cotidianidad de los sujetos es alterada por los dispositivos de justicia transicional, pasan de ser vidas que transcurrían de forma «tranquila» a estar en la mira de grupos armados, afectando el tejido social de sus comunidades. De esta manera, los sujetos se ven inmersos en una serie de discursos y prácticas estatales que interpelan sus subjetividades, dando como resultado procesos de subjetivación política con matices étnicos en los cuales los sujetos agencian y reivindican sus derechos,

[142] y a su vez, se dan interpretaciones propias que colonizan esas prácticas y discursos estatales.

Investigador: ¿Cómo era el día a día de Juan antes de empezar el proceso de restitución y cómo es esa rutina hoy?

Juan: Antes de estar en este proceso yo trabajaba en una cooperativa y también estaba mucho en mi casa. En esa cooperativa trabajaba cargando barcos con madera, cuando no estaba en eso estaba jugando domino, rumí o billar, también hacía oficios varios, de todero. Hoy, un día normal en este proceso es un día de reuniones, ya sea con alguna entidad o con comunidades, ese es un día normal. Ahora ando en una camioneta con mis compañeros, es un esquema de seguridad, ahora toca cuidarse por ser reclamante (comunicación personal, Juan Marín, miembro de la junta directiva Cocolatu, septiembre 14, 2019).

De esta manera, la puesta en marcha de los diferentes dispositivos de justicia transicional derivó en complejos espacios sociales desde donde brotan procesos de subjetivación política étnica, los cuales se arraigan en los registros y enunciados producidos en el marco del pluralismo transicional. El caso de Borlín Valencia ilustra lo anterior. Borlín fue el representante legal de 
Cocolatu en 2011, desde donde abanderó el inicio del proceso de restitución de derechos étnico-territoriales. Esta experiencia le permitió adquirir una serie de conocimientos técnicos y a gestionar trámites burocráticos, permitiéndole proyectarse como un líder de la subregión y construir una plataforma política para postularse como candidato a la Alcaldía de Riosucio en 2019, lo cual es muestra de una suerte de ciudadanía liminal, ${ }^{7}$ es decir, «aquella en la cual los sujetos transitan entre instituciones estatales y no estatales, no son del todo ciudadanos y pareciera que no lo serán, o al menos no al modo clásico del liberalismo político» (García, 2017, p. 43).

Los habitantes de Cocolatu, al ser una población que sufrió el flagelo del desplazamiento forzado, tuvieron que asistir a entidades públicas y realizar trámites que les formaron una idea de cómo funciona el aparato estatal. Resulta contradictorio e irónico, pero es la experiencia del desplazamiento y la exigencia de sus derechos étnico territoriales la que los acerca a una ciudadanía en tránsito, suspendida en la liminalidad. La forma en que estas personas participan políticamente está impregnada de prácticas y discursos técnicos, producto del proceso de etnización de las comunidades negras, los dispositivos transicionales y elementos del derecho propio:

Investigador: ¿Cómo ha sido el proceso de entender todo ese lenguaje y trámites de la restitución?

Lucas: Ese proceso de ir a reuniones y entender eso es confuso al inicio, es muy enredador, yo escuchaba hablar, pero no entendía, ya hoy entiendo más cosas, cómo va el proceso, en qué etapa va. Yo pude abrir los ojos con eso, me di cuenta de que nosotros como comunidades negras fuimos tenidos en cuenta, pero a raíz del desplazamiento y de la Ley 70, en parte, sino fuera por eso, hasta ahora nada. Eso también le sirvió a los chilapos [mestizos] (comunicación personal, Lucas Gaitán, miembro de la junta directiva Cocolatu, septiembre 12, 2019).

De esta forma, los dispositivos de justicia transicional en Cocolatu operan en un contexto en el que, aparte del recrudecimiento de la violencia, hay una serie de marcadores de diferencia que generan una jerarquización de esta y procesos de subjetivación política en los cuales se recrea el Estado desde abajo —donde las prácticas estatales son colonizadas—, dándose una resignificación de la transición. Lo anterior se evidencia en las reuniones

\footnotetext{
${ }^{7}$ Cabe recordar la utilidad de esta categoría, formulada por Victor Turner (1974) y Arnold van Gennep (1909) para describir la forma en que en los rituales religiosos hay un momento o estado en el cual el sujeto está en tránsito, queda suspendido, marginado de la estructura social.
} 
sostenidas con la URT, en las cuales el conocimiento técnico sobre el proceso de restitución es un factor clave, a esto se suma el clivaje «raza» como lugar de enunciación y legitimidad de «lo étnico», ya que «el multiculturalismo oficial no necesariamente conduce a la disminución del racismo y puede quedarse en gestos retóricos. Es necesario enfocar el racismo y el concepto de raza como fenómenos con historia y fuerza social propias» (Wade, 2011, p. 16).

\section{Conclusiones}

Los dispositivos transicionales implementados en Colombia son un trasplante de modelos adoptados en el ámbito global y elaborados por los formuladores de política pública, donantes, organismos multilaterales y la academia, por lo que muchos de ellos responden a dinámicas de la globalización y del capitalismo contemporáneo. La profusa expansión del discurso transicional cada vez tiende a afincarse en conceptos universales y homogéneos, produciendo una serie de enunciados que se enmarcan en el derecho hegemónico, que poco responden a los contextos locales de las comunidades. Sin embargo, estos modelos de gobernabilidad y transición, a la hora de ser trasplantados localmente, sufren un dislocamiento a partir de la configuración cotidiana que se les otorga conceptos como verdad, justicia [144] y reparación.

Esto implica un ejercicio de interpretación y resignificación, es decir, un cambio de coordenadas sobre los discursos institucionales pregonados tanto por el sistema-Estado como por los organismos internacionales sobre el discurso transicional, dibujando un nuevo mapa desde sus experiencias vitales y su entramado cultural, que a su vez le otorgan un horizonte de sentido a estos conceptos, despojándolos de tecnicismos jurídicos, lo cual permite ser agenciados en la cotidianidad. A través de la etnográfica de lo transicional se evidencia cómo las comunidades negras de Cocolatu, a partir de un ejercicio de derecho propio y autogobierno, generan una disrupción con las narrativas transicionales.

En este orden de ideas, los habitantes de Cocolatu viven el proceso de transición en medio de diversos conflictos con grupos armados y terratenientes, tensiones étnico-raciales producto de la Ley 70, lo cual generó procesos de subjetivación política étnica que fueron reforzados por los dispositivos transicionales. Pese a esto, las comunidades negras consiguen apropiarse de la legalidad dominante, adecuándola a sus propios lenguajes, tornando el derecho en una herramienta de legitimación de saberes y órdenes, que 
desde la cotidianidad agencian contrapoderes y resistencias, produciendo lo que aquí se denomina pluralismo jurídico transicional, es decir, una serie de prácticas socioculturales mediante las cuales las comunidades negras disputan y negocian las narrativas transicionales.

Finalmente, es necesario producir conocimiento situado e interseccional que tenga en cuenta clivajes como la raza, la clase, el género y la etnia para analizar los procesos de transición, ya que esto permite generar representaciones científicas de la realidad social mucho más acordes a esta. Esto permitiría entrever la forma en que esos dispositivos operan y se dislocan en territorios con procesos históricos particulares, resaltando las formas en que se presentan esas negociaciones sociales sobre el pasado, el presente y el futuro. Asimismo, resulta altamente recomendable articular la agenda investigativa de las desigualdades con las etnografías de lo transicional, complementando el lente analítico sobre los efectos de la acumulación, diferenciación social y marginalidad en la cotidianidad de los procesos de transición.

\section{Referencias bibliográficas}

1. Abrams, Philip. (2015). Notas sobre la dificultad de estudiar el Estado. En: Abrams, Philip; Gupta, Akhil y Mitchell, Timothy (eds.). Antropología del Estado (pp. 17-70). México, D. F.: Fondo de Cultura Económica.

2. Ariza, Rosembert. (2010). El derecho profano: justicia indígena, justicia informal y otras maneras de realizar lo justo. Bogotá, D. C.: Universidad Externado de Colombia.

3. Bourdieu, Pierre. (2000). Elementos para una sociología del campo jurídico. En: Bourdieu, Pierre y Teubner, Gunther. La fuerza del derecho (pp. 153-216). Bogotá, D. C.: Siglo del Hombre.

4. Castillejo, Alejandro. (2014). La localización del daño: etnografía, espacio, y confesión en el escenario transicional colombiano. Horizonte Antropológico, 20 (42), pp. 213-236. https://doi.org/10.1590/S0104-71832014000200009

5. Castillejo, Alejandro. (2017). La ilusión de la justicia transicional: perspectivas críticas desde el sur global. Bogotá, D. C.: Universidad de los Andes. https://doi. org/10.7440/2017.25

6. Centro de Investigación y Educación Popular Programa por la Paz (Cinep/PPP). (2015). Caracterización de afectaciones territoriales Consejo Comunitario de los Ríos La Larga y Tumaradó. Bogotá, D. C.: Cinep/PPP.

7. Cohen, Néstor y Piovani, Juan Ignacio. (2008). La metodología de la investigación en debate. Buenos Aires: EDULP, Eudeba.

8. Colombia. Congreso de la República. Ley 70. (27 de agosto de 1993). Por la cual se desarrolla el artículo transitorio 55 de la Constitución Política. Recuperado de 
https://www.mininterior.gov.co/la-institucion/normatividad/ley-70-de-1993-agosto27-por-la-cual-se-desarrolla-el-articulo-transitorio-55-de-la-constitucion-politica

9. Colombia. Congreso de la República. Ley 387. (18 de julio de 1997). Por la cual se adoptan medidas para la prevención del desplazamiento forzado; la atención, protección, consolidación y esta estabilización socioeconómica de los desplazados internos por la violencia en la República de Colombia. Recuperado de https://www. unidadvictimas.gov.co/sites/default/files/documentosbiblioteca/ley-387-de-1997.pdf

10. Colombia. Congreso de la República. Ley 975. (25 de julio de 2005). Por la cual se dictan disposiciones para la reincorporación de miembros de grupos armados organizados al margen de la ley, que contribuyan de manera efectiva a la consecución de la paz nacional y se dictan otras disposiciones para acuerdos humanitarios. Recuperado de http://www.secretariasenado.gov.co/senado/basedoc/ley_0975_2005. html

11. Colombia. Congreso de la República. Ley 1448. (10 de junio de 2011). Por la cual se dictan medidas de atención, asistencia y reparación integral a las víctimas del conflicto armado interno y se dictan otras disposiciones. Recuperado de http://www. secretariasenado.gov.co/senado/basedoc/ley_1448_2011.html

12. Colombia. Instituto Colombiano de la Reforma Agraria. Resolución 02805. (22 de noviembre de 2000). Por medio de la cual se adjudican en calidad de «Tierras de Comunidades Negras», los terrenos baldíos ocupados colectivamente por la Comunidad Negra, organizada en el Consejo Comunitario de los Ríos La Larga y Tumaradó, ubicados en jurisdicción del municipio de Riosucio, departamento del Chocó. Recuperado de https://diario-oficial.vlex.com.co/vid/resolucion-02805-43149592

13. Colombia. Ministerio del Interior. Decreto 4635. (9 de diciembre de 2011). Por el cual se dictan medidas de asistencia, atención, reparación integral y de restitución de tierras a las víctimas pertenecientes a comunidades negras, afrocolombianas, raiza/ es y palenqueras. Recuperado de https://www.unidadvictimas.gov.co/sites/default/ files/documentos_biblioteca/DECRETO\%204635\%20NEGROS-AFROS-RAIZALESPALENQUEROS.p̄jf

14. Colombia. Tribunal Superior de Medellín. Sala de Justicia y Paz. Sentencia 1100160002532008 83241. (27 de agosto de 2014). Recuperado de https://www. minsalud.gov.co/sites/rid/Lists/BibliotecaDigital/RIDE/DE/DIJ/sentencia-bloque-elmercardenas-dario-enrique-velez-y-otros.pdf

15. Comisión Colombiana de Juristas. (2011). Despojo de tierras campesinas y vulneración de los territorios ancestrales. Bogotá, D. C.: GIZ.

16. Consejo Comunitario de los Ríos La Larga y Tumaradó (Cocolatu). (2018). Reglamento Interno del Consejo Comunitario de los Ríos La Larga y Tumaradó (Cocolatu). Manuscrito inédito.

17. Das, Veena y Poole, Debora. (2008). El estado y sus márgenes. Etnografías comparadas. Cuadernos de Antropología Social, 27. pp. 3-35. Recuperado de https:// www.redalyc.org/pdf/1809/180913917002.pdf 
18. Defensoría del Pueblo. (2020, marzo 6). Alerta temprana N. ${ }^{\circ} 009$. Indepaz. Recuperado de http://www.indepaz.org.co/wp-content/uploads/2020/05/AT$\mathrm{N} \% \mathrm{C} 2 \%$ B0-009-2020-CHO-Carmen-del-Darien-y-Riosucio.pdf

19. Derrida, Jacques. (2008). Fuerza de ley. El fundamento mistico de la autoridad. Madrid: Tecnos.

20. Fitzpatrick, Peter. (2011). El derecho como resistencia: modernismo, imperialismo, legalismo. Bogotá, D. C.: Siglo del Hombre.

21. García, Julián Esteban. (2017). «Dios nos guía»: teodicea del desplazamiento forzado y ciudadanías liminales. Maguaré, 31 (2), pp. 195-224. https://doi. org/10.15446/mag.v31n2.71539

22. García, Julián Esteban. (2019). El Acuerdo de Paz de La Habana. Un cambio institucional ambicioso con una estrategia dudosa. Estudios Políticos, 55. pp. 182204. https://doi.org/10.17533/udea.espo.n55a09

23. Gobierno de Colombia y FARC-EP. (2016). Acuerdo final para la terminación del conflicto y la construcción de una paz estable y duradera. Recuperado de https:// www.cancilleria.gov.co/sites/default/files/Fotos2016/12.11_1.2016nuevoacuerdofin al.pdf

24. Goffman, Erving. (1959). The Presentation of Self in Everyday Life. New York: Bantam Doubleday.

25. Guber, Rosana. (2008). El salvaje metropolitano. Reconstrucción del conocimiento social en el trabajo de campo. Buenos Aires: Paidós.

26. Gupta, Akhil. (2015). Fronteras borrosas: el discurso de la corrupción, la cultura de la política y el estado imaginado. En: Abrams, Philip; Gupta, Akhil y Mitchell, Timothy (eds.). Antropología del Estado (pp. 71-114). México, D. F.: Fondo de Cultura Económica.

27. Guerrero, Juan Pablo. (2018). Territorios en disputa: restitución de tierras en el Consejo Comunitario de La Larga y Tumaradó, subregión del bajo Atrato (Chocó). Bogotá, D. C.: Cinep/PPP, Pontificia Universidad Javeriana, Unión Europea.

28. Instituto Colombiano de la Reforma Agraria (Incora). (2000). Expediente de titulación Consejo Comunitario de los ríos La Larga y Tumaradó. Bogotá, D. C.: Incora.

29. Jessop, Bob. (2017). El estado pasado, presente y futuro. Madrid: Catarata.

30. Jimeno, Myriam; Sotomayor, María Lucía y Valderrama, Luz María. (1995). Chocó: Diversidad cultural y medio ambiente. Bogotá, D. C.: Fondo FEN Colombia.

31. Krotz, Esteban (ed.). (2014). Sociedades, conflictos, cultura y derechos desde una pespectiva antropológica. En: Antropología jurídica: perspectivas socioculturales en el estudio del derecho. Barcelona: Anthropos, pp. 13-49.

32. Lemaitre, Julieta. (2009). El derecho como conjuro: Fetichismo legal, violencia y movimientos sociales. Bogotá, D. C.: Siglo del Hombre.

33. Lemaitre, Julieta. (2019). El Estado siempre llega tarde: la reconstrucción de la vida cotidiana despues de la guerra. Bogotá, D. C.: Siglo XXI. 
34. Osorio Granados, Marcela. (2019, agosto 2). Una apuesta por visibilizar la guerra del Bajo Atrato. El Espectador. Recuperado de https://www.elespectador.com/ noticias/nacional/una-apuesta-por-visibilizar-la-guerra-del-bajo-atrato/

35. Restrepo, Eduardo. (2011). Etnización y multiculturalismo en el bajo Atrato. Revista Colombiana de Antropología, 47 (2), pp. 37-68. https://doi. org/10.22380/2539472X.957

36. Rodríguez, César y Baquero, Carlos Andrés. (2015). Reconocimiento con redistribución: el derecho y la justicia étnico-racial en America Latina. Bogotá, D. C.: Dejusticia.

37. Ruiz-Giménez Arrieta, Itzar. (2012). El sueño liberal en en Africa Subsahariana. Madrid: Catarata.

38. Santos, Boaventura de Sousa (2009). Sociología jurídica crítica. Para un nuevo sentido común en el derecho. Bogotá, D. C.: ILSA.

39. Schutz, Alfred. (1993). La construcción significativa del mundo. Barcelona: Paidós.

40. Sharp, William. (1993). Manumisión, libres y resistencia negra en el Chocó colombiano. En: Pablo, Leyva (ed.). Colombia Pacífico Tomo I (pp. 406-419). Bogotá, D. C.: Fondo para la Protección del Medio Ambiente José Celestino Mutis.

41. Sierra, María Teresa y Chenaut, Victoria. (2014). Los debates recientes y actuales en la antropología juridica: las corrientes anglosajonas. En: Krotz, Esteban (ed.). Antropología jurídica: perspectivas socioculturales en el estudio del derecho.

[148] (pp. 113-170). Barcelona: Anthropos.

42. Teitel, Ruti. (2004). Genealogía de la justicia transicional. Biblioteca Virtual CEJA. Recuperado de https://biblioteca.cejamericas.org/handle/2015/2059?show = full

43. Trouillot, Michel-Rolph. (2001). The Anthropology of the State in the Age of Globalization. Current Anthropology, 42 (1), pp. 125-38. https://doi. org/10.1086/318437

44. Turner, Victor. (1974). On the Edge of the Bush. Anthropology as Experience. Tucson: University of Arizona.

45. Van Gennep, Arnold. (1909). The Rites of Passage. Chicago: University of Chicago.

46. Wade, Peter. (2011). Multiculturalismo y racismo. Revista Colombiana de Antropología, 47 (2), pp. 15-35.

Wolkmer, Angtonio Carlos. (2002). Sociedad civil, poder comunitario y acceso democrático a la justicia. El Otro Derecho, 26-27. pp. 135-147. 